\title{
Seroreactivity to new Mycobacterium leprae protein antigens in different leprosy-endemic regions in Brazil
}

\author{
Emerith Mayra Hungria', Regiane Morillas de Oliveira', \\ Ana Lúcia Osório Maroclo de Souzaㅁ, Maurício Barcelos Costa', Vânia Nieto Brito de Souza², \\ Eliane Aparecida Silva², Fátima Regina Vilani Moreno², Maria Esther Salles Nogueira², \\ Maria Renata Sales Nogueira Costa², Sônia Maria Usó Ruiz Silva², Samira Bührer-Sékula1, \\ Steven G Reed ${ }^{3}$, Malcolm S Duthie ${ }^{3}$, Mariane Martins de Araújo Stefani¹/+
}

\footnotetext{
1Instituto de Patologia Tropical e Saúde Pública, Universidade Federal de Goiás, Goiânia, GO, Brasil

${ }^{2}$ Instituto Lauro de Souza Lima, Bauru, SP, Brasil ${ }^{3}$ Infectious Disease Research Institute, Seattle, WA, USA
}

New Mycobacterium leprae protein antigens can contribute to improved serologic tests for leprosy diagnosis/classification and multidrug therapy (MDT) monitoring. This study describes seroreactivity to M. leprae proteins among participants from three highly endemic leprosy areas in Brazil: central-western Goiânia/Goiás (GO) $(n=225)$, Rondonópolis/Mato Grosso (MT) $(n=764)$ and northern Prata Village/Pará (PA) $(n=93)$. ELISA was performed to detect IgG to proteins (92f, 46f, leprosy IDRI diagnostic-1, ML0405, ML1213) and IgM to phenolic glycolipid-I (PGL-I). Multibacillary (MB) leprosy had positive rates for PGL-I that were similar to those for proteins; however, some anti-PGL-I-negative subjects were positive for proteins, suggesting that adding protein antigen to PGL-I can enhance the sensitivity of MB leprosy detection. In MT, different degrees of seroreactivity were observed and ranked for $M B$, former patients after MDT, paucibacillary (PB) leprosy, household contact (HHC) and endemic control (EC) groups. The seroreactivity of PB patients was low in GO and MT. HHCs from different endemic sites had similar IgG antibody responses to proteins. $46 f$ and $92 f$ were not recognised by most tuberculosis patients, ECs or HHCs within GO, an area with high BCG vaccination coverage. Low positivity in EC and HHC was observed in PA and MT. Our results provide evidence for the development of an improved serologic test that could be widely applicable for MB leprosy testing in Brazil.

Key words: leprosy - diagnosis - serology

In field conditions, the diagnosis and classification of leprosy is based on clinical manifestations of the disease and no specific and sensitive tests to detect $\mathrm{Myco}$ bacterium leprae infection are commercially available. The development of diagnostic tests for leprosy needs to take into account the wide spectrum of clinical manifestations, for which there is an inverse correlation between the bacterial index (BI) and cell-mediated immunity (CMI). The leprosy spectrum comprises multibacillary (MB) patients [including lepromatous (LL) and borderline lepromatous (BL)] who develop strong humoural responses, but weak CMI to M. leprae. At the other end of the spectrum, paucibacillary (PB) patients [tuberculoid (TT) and borderline tuberculoid (BT)] develop robust CMI, but weak or no humoural immunity

\footnotetext{
Financial support: DECIT/CNPq, Heiser Foundation for TB and Leprosy

EMH and RM de $\mathrm{O}$ were supported by scholarships from the CNPq and the CAPES, respectively, and MM de AS is a recipient of a fellowship from CNPq (310582/2011-3).

+ Corresponding author: mstefani@iptsp.ufg.br

Received 15 March 2012

Accepted 25 July 2012
}

to M. leprae (reviewed in Scollard et al. 2006). In between these polar forms of the disease, immunologically unstable patients with less effective CMI develop borderline leprosy forms [BT, borderline-borderline (BB) or BL]. In leprosy-endemic countries, household contacts (HHCs) of MB patients are at increased risk of developing leprosy and can present both CMI and humoural responses, indicating either protective immunity or priming of the immune system by repeated exposure to leprosy bacilli (Fine et al. 1997, BührerSékula et al. 2003, Sampaio et al. 2011). Therefore, based on the diverse immunological profiles observed within the leprosy spectrum and among exposed contacts, a combination of serologic tests with assays based on CMI responses against $M$. leprae antigens will likely be required for the detection of most forms of leprosy (Stefani 2008).

Multidrug therapy (MDT) for leprosy, having now been implemented for 30 years, led to a significant decline in the prevalence of this disease. However, its incidence is now stable and at high levels in many countries, indicating that active transmission still occurs (WHO 2011). In Brazil, great achievements in public health assistance and economic development have taken place in recent years (Barreto et al. 2011). However, leprosy remains an important public health problem, with 34,894 new cases reported in 2010 (WHO 2011). Brazil presents significant levels of inequality and regional differ- 
ences in leprosy detection, with the highest rates being reported in the northern and central-western regions (39.98 and 33.92 per 100,000 inhabitants, respectively) (MS/SVS 2011). For treatment decisions, a simplified classification system based on the number of skin lesions was proposed: those presenting fewer than six skin lesions are classified as PB patients, while those presenting six or more skin lesions are classified as MB patients. Different MDT regimens are used to treat PB and MB leprosy (WHO 1991); therefore, any laboratory test that could aid in the differentiation/classification of PB and MB patients may have an important impact on patient management by public health system.

The most extensively evaluated serologic test for leprosy is based on the detection of IgM antibodies against phenolic glycolipid-I (PGL-I), a membrane component exclusive to M. leprae (Bührer-Sékula et al. 1998). Anti-PGL-I positivity reflects the bacillary load: most MB patients are seropositive, while the majority of PB patients are seronegative (Young \& Buchanan 1983, Bührer-Sékula et al. 2003). Although anti-PGL-I serology has limited application for the diagnosis of all clinical forms of leprosy, it has been suggested as an important adjunct tool for the differentiation of $\mathrm{PB}$ and MB leprosy (Bührer-Sékula et al. 2000, 2007). More recently, in the post-genomic era, data regarding seroreactivity to novel $M$. leprae protein antigens have been generated in various populations worldwide. Similar to anti-PGL-I serology, the presence of IgG antibodies that react to protein antigens reflects the leprosy spectrum and the bacillary load: most MB patients have high IgG titres, but few PB patients are responsive (Spencer et al. 2005, Araoz et al. 2006a, b, Geluk \& Ottenhoff 2006, Reece et al. 2006, Duthie et al. 2007, 2010, Geluk et al. $2009,2010)$. A significant decay in specific antibody responses occurs after MDT, suggesting that serology may be useful to monitor MDT (Silva et al. 2007, Duthie et al. 2011). Despite abundant new information, serologic reactivity to other novel $M$. leprae antigens, including new fusion proteins, remains to be shown (Duthie et al. 2008b, 2010). With or without PGL-I, these new protein antigens represent candidates for the development of improved serologic tests with enhanced specificity and sensitivity for leprosy diagnosis/classification and MDT monitoring.

The ideal solution would be a sensitive, specific, simple and robust diagnostic test that could be widely used in the field in leprosy-endemic regions without regard to the ethnic/genetic background of the population. However, distinct human leukocyte antigen (HLA) alleles, which are differently distributed among populations, can interfere with the immunological reactivity to these proteins and this represents a potential limitation for the widespread implementation of such tests (Geluk et al. 2009). In this context, this study describes the serologic evaluations of two new M. leprae fusion antigens and extends the testing of four $M$. leprae recombinant antigens to large panels of leprosy patients and controls with diverse ethnic backgrounds who were recruited from regions of Brazil in which leprosy is highly endemic.

\section{SUBJECTS, MATERIALS AND METHODS}

Study area demographics - This study included a total of 1,072 participants recruited from three different leprosy-endemic settings in Brazil: Goiânia, state of Goiás (GO), Rondonópolis, state of Mato Grosso (MT) and Prata Village, state of Pará (PA) (Fig. 1). These three settings each have a different human development index (HDI), which is calculated from a combination of life expectancy at birth, mean years of schooling and gross national income per capita. The highest HDI score worldwide is 1.0.

The main features of the recruitment sites were the following: (i) Goiânia $(1,256,514$ inhabitants, HDI = 0.832) (IBGE 2010), (ii) Rondonópolis (195,476 inhabitants, HDI $=0.791$, considered a hyperendemic area for leprosy (MS/SVS 2009) and (iii) Vila do Santo Antônio do Prata/Prata Village (approximately 2,000 inhabitants) located in the municipality of Igarapé-Açú $(35,843$ inhabitants, HDI = 0.67), PA, Amazonian Basin (IBGE 2010).

Rondonópolis is one of the 11 municipalities prioritised for leprosy control due to increases in both newly diagnosed individuals younger than 15 years $(\geq$ $10 / 100,000$ inhabitants in 2009) and in grade 2 disability at diagnosis (MS/SVS 2009). Prata Village is a former leprosy colony created in 1920 and although compulsory isolation ended in 1962, this population has remained isolated. This site is one of several "hot pockets" of leprosy within PA, where a preliminary assessment indicated $12.82 \%$ leprosy prevalence (Lázaro et al. 2010). Leprosy is related to social and material inequalities (Kerr-Pontes et al. 2004) and Prata Village, which had the lowest HDI of all the study sites, presented the highest leprosy prevalence among the three tested sites.

Brazil has a multi-racial population comprising a confluence of descendants of native Indians, Portuguese colonisers and West African slaves and, more recently, additional European, Arab and Japanese immigrants. The

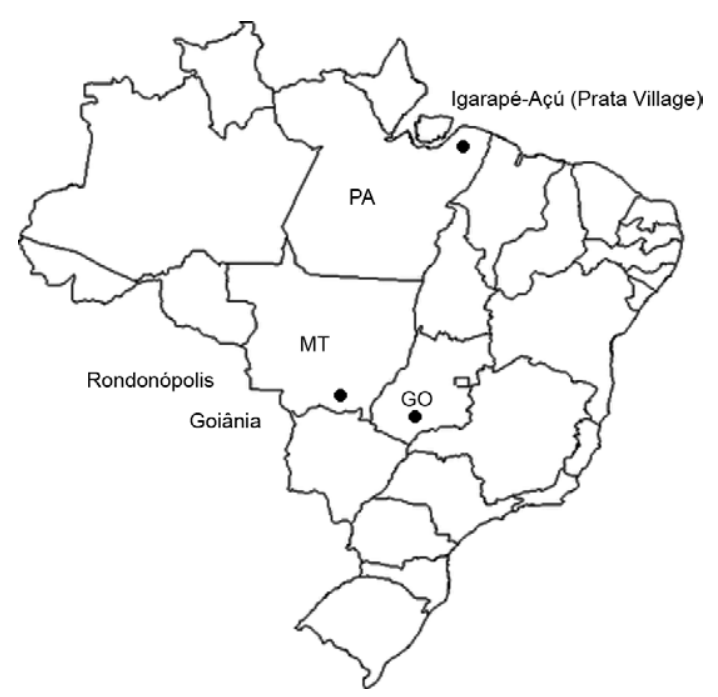

Fig. 1: geographical localization of the three Brazilian leprosy endemic study areas: Iguarapé-Açú/Prata Village, state of Pará (PA), northern region, Rondonópolis, state of Mato Grosso (MT), and Goiânia, state of Goiás (GO), in central-western Brazil. 
population in GO is composed mainly of persons that declare themselves to be white or mixed white and black. In contrast, in PA, mixed white and black individuals are the main group $(>70 \%)$ and black Afro descendants from slaves represent a substantial component of the population (IBGE 2010). PA and MT are also among the states with the highest concentrations of native Brazilian Indians, with approximately 30,000 Indian individuals from more than 30 different ethnicities in PA alone.

Study groups - In this study, all newly diagnosed leprosy patients were classified according to the Ridley and Jopling (1966) criteria, taking into consideration clinical, bacilloscopic and histopathologic data. All participants signed an informed consent before blood was collected. Serum samples were stored at $-20^{\circ} \mathrm{C}$ and sent to Institute of Tropical Pathology and Public Health, Federal University of Goiás (UFG), where all serologic tests were performed. At each site, participants from both sexes and of any age were included. Serum samples were collected from 2006-2010.

Participants from GO were recruited at the main outpatient clinic (Reference Center for Diagnostics and Therapeutics, Goiânia) and included the following study groups: (i) newly diagnosed, untreated leprosy patients (PB, $n=45 ; M B, n=45)$, (ii) healthy HHCs of MB leprosy patients $(n=45)$, defined as healthy individuals who have shared a house with the index case for at least six months, (iii) healthy endemic controls $(\mathrm{ECs})(\mathrm{n}=45)$ who had no previous tuberculosis (TB) diagnosis or known contact with leprosy patients, (iv) pulmonary TB patients with confirmed bacilloscopy, who were seronegative for human immunodeficiency virus (HIV)-1/2 and under specific therapy for at least three months $(n=45)$.

Study groups from Rondonópolis included the following: (i) newly diagnosed, untreated leprosy patients $(\mathrm{n}=151,58 \mathrm{MB} / 93 \mathrm{~PB})$ recruited at Dermatology Center Jardim Guanabara, (ii) healthy HHCs of MB leprosy patients $(\mathrm{n}=192)$, (iii) healthy ECs $(\mathrm{n}=282)$ and (iv) individuals previously diagnosed with MB leprosy who completed MDT between 1990-2006 (post-MDT, $\mathrm{n}=139$ ).

Study groups from Prata Village included the following: (i) healthy HHCs of MB leprosy patients $(n=36)$, (ii) previously diagnosed MB leprosy patients who completed MDT between 1990-2006 (post-MDT, $\mathrm{n}=47$ ).

Detection of antibodies to M. leprae antigens - Serum IgG antibodies to $M$. leprae protein antigens were detected by ELISA. The seroreactivities of the di-fusion protein leprosy IDRI diagnostic-1 (LID-1) and the recombinant ML0405 protein, both previously described by our group as immunogenic and capable of inducing specific responses among leprosy patients (Reece et al. 2006, Duthie et al. 2007), as well as the seroreactivities of two novel $M$. leprae fusion proteins (46f, a di-fusion of the ML0568 and ML0405 proteins and 92f, a tri-fusion of the ML2028, ML2346 and ML1862 proteins), were evaluated. The previously described non-immunogenic ML1213 recombinant protein was used as a negative control (Reece et al. 2006). In brief, PolySorp 96-well plates (Corning Costar, NY, USA) were coated with
$2 \mu \mathrm{g} / \mathrm{mL}$ of each individual recombinant protein at $4^{\circ} \mathrm{C}$ and blocked with phosphate-buffered saline (PBS) with Tween-20 with $1 \%$ bovine serum albumin (BSA). Serum samples diluted $1 / 200$ in $0.1 \%$ BSA were added in duplicate and incubated for $2 \mathrm{~h}$ at room temperature. These plates were washed and incubated with horseradish peroxidase (HRP)-conjugated anti-human IgG (Southern Biotech, Birmingham, AL). After washing, reactions were developed with peroxidase colour substrate (KPL, Gaithersburg, MD, USA) and quenched by the addition of $1 \mathrm{~N} \mathrm{H}_{2} \mathrm{SO}_{4}$. The corrected optical density (OD) of each well at $450 \mathrm{~nm}$ was determined using a Multiskan Ex microplate reader (Thermo Scientific, USA). Based on previous data, the threshold for positive responses was calculated to be $2 \times$ standard deviation of the OD of sera from healthy ECs, such that samples with OD $>0.3$ were considered positive (Duthie et al. 2007). The specificity of the response was defined by low $(<10 \%)$ recognition by sera from TB patients and ECs. The results are expressed as the mean OD of duplicates.

Serum IgM antibodies to $M$. leprae PGL-I were similarly detected by ELISA. PolySorp 96-well plates (Nunc, Roskilde, Denmark) were coated with $0.01 \mathrm{mg} / \mathrm{mL}$ of the natural trisaccharide-phenyl synthetic analogue of PGL-I conjugated to BSA (NT-P-BSA) (kindly provided by Dr Fujiwara, Nara University, Japan) and blocked with $1 \%$ BSA/PBS. Serum samples diluted $1 / 300$ in $1 \%$ BSA were tested in duplicate with either NT-P-BSA or BSAcoated wells. After incubation and washing, HRP-conjugated anti-human IgM (Immuno Chemicals, St. Louis, Missouri, USA) was added. After incubation and washing, peroxidase colour substrate (KPL, Gaithersburg, MD, USA) was added and the reaction was quenched by the addition of $2.5 \mathrm{~N} \mathrm{H}_{2} \mathrm{SO}_{4}$. The OD was determined at $450 \mathrm{~nm}$ using a Multiskan Ex microplate reader (Thermo Scientific, San Jose, California, USA).

Statistical analyses - GraphPad Prism (version 5) and MS Excel (2007) were used to calculate the median and mean OD values and to construct dot blot graphics. Statistical significance was assessed using the Kruskal-Wallis one-way analysis of variance for comparison of multiple groups and by the Mann-Whitney $U$ test for comparison between two groups. Results were considered statistically significant when $\mathrm{p}$ values $<0.05$ were obtained.

Ethical issues - This study was approved by the following boards: Ethics in Human and Animal Research of Clinics Hospital of UFG (protocol \#4862), Brazilian Research Ethics Commission (protocol \#12962) and the Ethics Committee of Lauro de Souza Lima Institute (protocol \#172/09). For participants under 18 years of age, the informed consent form was signed by one of the patient's parents or by his or her legal guardian.

\section{RESULTS}

Seroreactivity to novel M. leprae fusion proteins Serologic reactivity to the novel $M$. leprae fusion proteins $46 \mathrm{f}$ and $92 \mathrm{f}$ was assessed among 225 participants from Goiânia who were categorised into one of five groups: $\mathrm{MB}, \mathrm{PB}, \mathrm{HHC}, \mathrm{EC}$ or TB (45 individuals per 
group) (Fig. 2A, B). The MB patient group included 16 $\mathrm{LL}$, nine $\mathrm{BL}$ and $20 \mathrm{BB}$ forms (median $\mathrm{BI}=4$ ), with a median age of 52 years and a majority of males. The PB patient group was comprised of 16 TT and 29 BT patients, with a median age of 41 years and a majority of females. In the $\mathrm{HHC}$ and $\mathrm{EC}$ groups, the median ages were 35 and 27 years, respectively, and similar proportions of males and females were included. Among TB patients, the median age was 36 years and the majority were male. BCG vaccination coverage was high in Goiânia and this was reflected in each study group. BCG scars were detected in $84.4 \%(38 / 45)$ of the TB patients, $89 \%$ of the PB leprosy patients (40/45), $80 \%$ (36/45) of the MB leprosy patients, $100 \%$ of the HHCs and $97.8 \%(44 / 45)$ of the ECs.

Regarding the $46 \mathrm{f}$ antigen (Fig. 2A), most MB leprosy patients $(86.6 \%, 39 / 45)$ had detectable IgG antibodies (median $\mathrm{OD}=1.33$, range $0.17-2.31)$ and $33.3 \%(15 / 45)$ of PB leprosy patients were seroreactive (median OD = 0.23 , range $0.16-0.73$ ). Serological recognition by HHCs, ECs and TB patients was low, ranging from 3\% in ECs (median $\mathrm{OD}=0.14)$ to $5 \%$ in $\mathrm{HHCs}($ median $\mathrm{OD}=0.24)$ to $4 \%$ in TB patients (median OD $=0.29$ ).

The serologic reactivity to $92 \mathrm{f}$ (Fig. $2 \mathrm{~B}$ ) was statistically different among MB, PB, TB, EC and HHC groups $(\mathrm{p}<0.0001)$. Most MB leprosy patients were seroreactive $(64.4 \%, 29 / 45)($ median OD $=0.36$, range $0.13-1.75)$ and $22.2 \%(10 / 45)$ of PB patients were positive (median $\mathrm{OD}=0.18$, range $0.11-0.78$ ). Unlike the $46 \mathrm{f}$ proteins, the responses to which were evenly distributed, the $92 \mathrm{f} \mathrm{fu}-$ sion proteins resulted in clearly divided subsets of positive and negative responses within the MB group. However, recognition by the $\mathrm{HHC}, \mathrm{TB}$ and $\mathrm{EC}$ groups ranged from $4-8 \%$ at low median ODs: $\mathrm{HHC}=0.17, \mathrm{~TB}=0.17$ and $\mathrm{EC}=0.16$.

In these groups, positive anti-PGL-I serology was $84 \%$ for MB leprosy patients (38/45, OD range 0.08 2.76 ) and $9 \%$ for $\mathrm{PB}$ leprosy patients $(4 / 45$, OD range $0-0.95)$. Antibodies to PGL-I were detected in $4 \%$ of TB patients $(2 / 45$, OD range $0-0.30), 2 \%$ of ECs $(1 / 45$, OD range $0.02-0.31)$ and $7 \%$ of HHCs (3/45, OD range $0-0.53)$ (Fig. 2C).
Expanded serologic testing for M. leprae proteins: Rondonópolis - To expand both the number and the geographic distribution of participants, we tested sera from 764 individuals recruited in Rondonópolis, one of the 11 municipalities prioritised for leprosy control (MS/SVS 2009). In Rondonópolis, most MB and PB leprosy patients were male and were older than the HHCs and ECs. Post-MDT participants had a median age of 53 years.

ML0405, LID-1 and 46f were recognised by over $80 \%$ of the MB patients (Fig. 3). The highest positive recognition rate was observed for LID-1 protein (89\%) (Fig. 3A). The median OD for LID-1 was 1.60, for ML0405 was 1.81 and for $46 f$ was 1.26 ( $p<0.0001$ vs. EC). In this MB group, the positive rate for $92 \mathrm{f}$ was lower than that of the other proteins assessed (59\%) (median OD $=0.43$, range 0.05-2.66). Most MB patients from Rondonópolis $(83 \%, 48 / 58)$ were also positive for anti-PGL-I serology (median $\mathrm{OD}=0.74$, range $0.03-1.55$ ).

Low levels of both IgG antibodies to M. leprae proteins and IgM antibodies to PGL-I were observed among the 93 PB patient sera from Rondonópolis (Fig. 3C). Regarding seropositivity, $7-16 \%$ of PB patients were responsive, with the highest positive rate detected for $92 \mathrm{f}$ protein $(16 \%, 15 / 93$, median $\mathrm{OD}=0.13$, range $0.01-0.98)$. The PGL-I-positive rate among PB patients was $8 \%$ $(7 / 93$, median OD $=0.03$, range 0.01-0.51). Table summarises positivity rates in the ELISAs and the OD details for LID-1 fusion protein and PGL-I antigen among untreated MB and PB leprosy patients from Rondonópolis.

The positivity rate for all antigens was low among HHCs and ECs. For HHCs, positivity for different $M$. leprae proteins ranged from $4-7 \%$, with the highest positive rate for $92 \mathrm{f}$ protein, while $3 \%$ were anti-PGL-I positive. ECs had a higher positivity rate for anti-PGL-I ( $9 \%$ ) than for M. leprae proteins (approximately 3\%) (Fig. 3D, E).

In agreement with previous observations indicating that antigen-specific responses wane upon treatment (Duthie et al. 2011), the seroreactivity of previously diagnosed MB leprosy that completed MDT four-20 years prior to testing $(\mathrm{n}=139)$ was lower than observed among unmatched, untreated MB patients (17-45\% reactivity among post MDT vs. $59-89 \%$ reactivity among
A

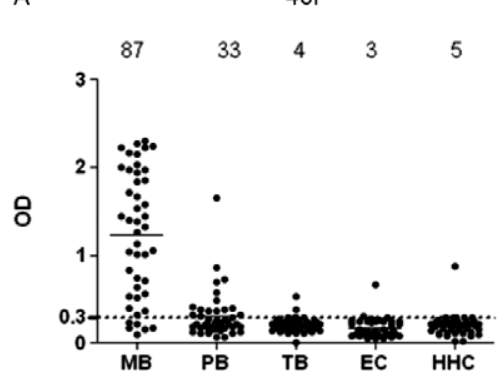

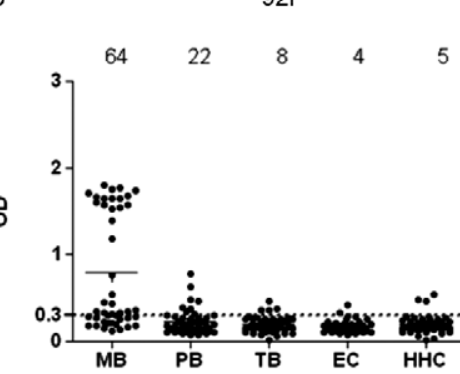

C

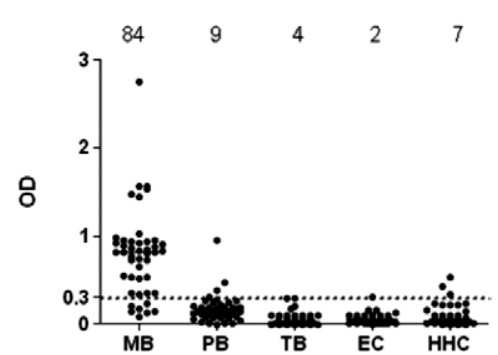

Fig. 2: antibody responses in Goiânia, state of Goiás, in central-western Brazil. Serologic reactivity to $46 \mathrm{f}$ protein (A), 92f protein (B) and phenolic glycolipid-I (PGL-I) (C). Newly diagnosed untreated multibacillary (MB) and paucibacillary (PB) leprosy patients, tuberculosis (TB) patients, endemic controls (EC) and household contacts (HHC) of MB patients. IgG antibodies to Mycobacterium leprae protein antigens (92f, 46f) and IgM antibodies to PGL-I were detected by ELISA tests. Each point represents the mean optical density (OD) of duplicates of an individual serum sample and the median OD value of each group is represented by the horizontal line. The traced horizontal line is the cut-off (OD $>0.3$ ). The number above each data set is the percent positive responses. 
untreated MB) (Fig. 3B). In the post-MDT group, the median ODs for protein antigens were also lower than those observed for untreated MB leprosy patients: 0.25 for LID-1, 0.20 for ML0405, 0.28 for 46f and 0.24 for 92f. Approximately $14 \%$ of post-MDT individuals were anti-PGL-I positive (median OD $=0.03$ ). To measure the effect of time post-MDT on the decline of antibody levels to protein antigens among previously diagnosed MB leprosy patients from Rondonópolis, participants were stratified according to the number of years posttreatment: four-five years $(\mathrm{n}=27)$, six-10 years $(\mathrm{n}=70)$, $11-15$ years $(\mathrm{n}=38)$ and $16-20(\mathrm{n}=4)$. No correlation was observed between the number of years post-treatment and seroreactivity to the proteins tested (Kruskal Wallis $\mathrm{p}>0.05$, data not shown).

Serologic reactivity among participants from Prata Village - The seroreactivity of 83 participants from Prata Village, a former leprosy colony that remains a leprosy "hot pocket" (Lázaro et al. 2010), was assessed. PostMDT individuals were older than HHCs (median ages of 46 and 23 years, respectively) and both groups included similar numbers of males and females. The positivity rate in individuals from Prata Village who had leprosy and had completed MDT $(n=47)$ in the past $(4-20$ years ago) ranged from $33-50 \%$ (35\% for LID-1, $50 \%$ for $46 f$, $33 \%$ for ML0405 and $50 \%$ for $92 \mathrm{f}$ ) (Fig. 4A). In this post-MDT group, $8 \%$ were positive for anti-PGL-I serology. Though $11 \%$ of HHCs were anti-PGL-I positive, a low (3-8\%) to absent response to $M$. leprae proteins was observed in this group (Fig. 4B).
The effect of time post-MDT on the seroreactivity to protein antigens in individuals previously diagnosed with MB leprosy from Prata Village was assessed by patient stratification according to the number of years posttreatment: four-five years $(n=5)$, six-10 years $(n=32)$ and 11-20 $(\mathrm{n}=10)$. No correlation was observed between the number of years post-treatment and antibody levels to proteins (Kruskal Wallis $\mathrm{p}>0.05$, data not shown).

\section{DISCUSSION}

The results from this study demonstrate that the evaluation of the serologic reactivity to new M. leprae antigens among distinct populations from a highly endemic country with a multiracial population is a robust strategy to identify potential antigen targets for the development of new serologic tests for leprosy. Recently, several $M$. leprae protein antigens that are recognised by antibodies of leprosy patients have been described (Spencer et al. 2005, Araoz et al. 2006a, b, Geluk \& Ottenhoff 2006, Reece et al. 2006, Duthie et al. 2007, 2010, Geluk et al. 2009, 2010). However, the screening phase has not yet concluded because the new generation of fusion protein antigens has expanded the number of potential new antigens to be tested. Our group has described, in specific populations, new protein antigens, including fusion proteins, suitable for the development of improved serologic tests for leprosy. The cell-mediated immune responses to the $46 \mathrm{f}$ and $92 \mathrm{f} M$. leprae fusion proteins tested in this study were previously described (Duthie et al. 2008a, Sampaio et al. 2011). In the current study, we describe the humoural responses to the $46 \mathrm{f}$ and $92 \mathrm{f} M$. leprae fu-
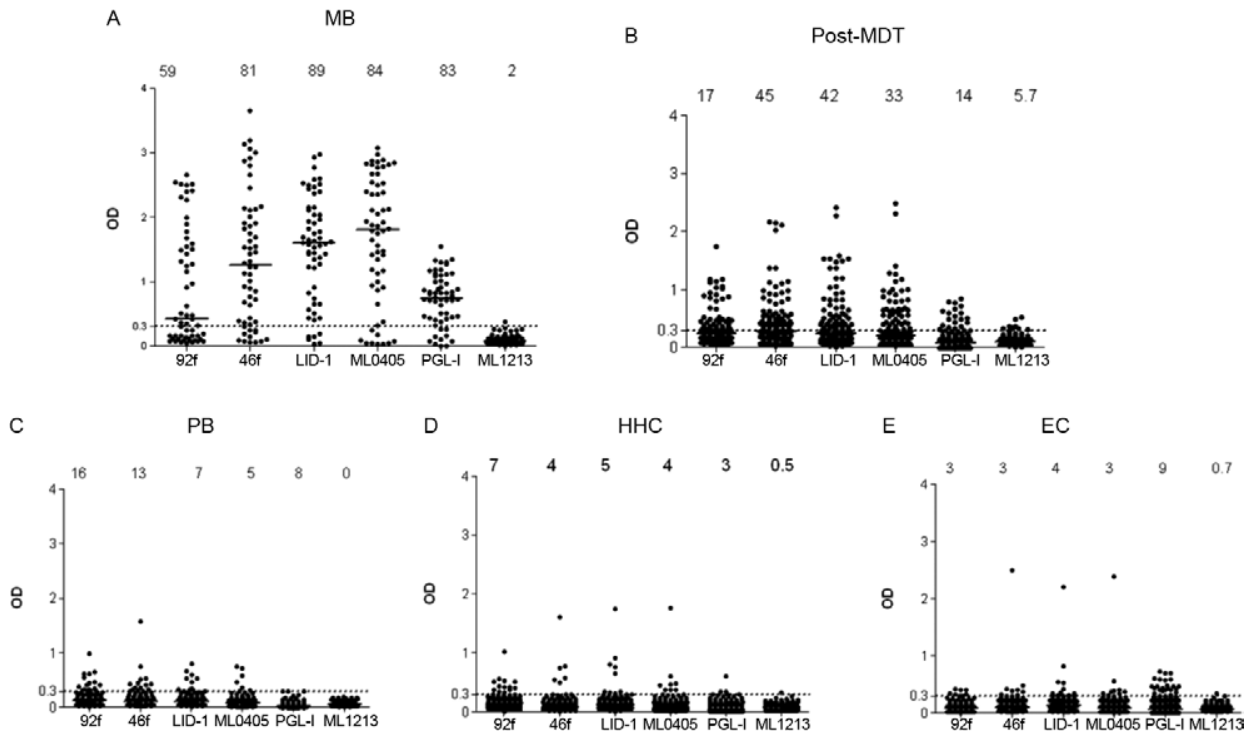

Fig. 3: serologic reactivity to Mycobacterium leprae protein antigens - 92f, 46f, leprosy IDRI diagnostic-1 (LID-1), ML0405 phenolic glycolipid-I (PGL-I) and ML1213 - among participants from Rondonópolis, state of Mato Grosso, in central-western Brazil. A: newly diagnosed untreated multibacillary (MB) leprosy patients $(\mathrm{n}=58)$; B: post-multidrug therapy (MDT) $(\mathrm{n}=139)$ individuals previously diagnosed as MB leprosy that received MDT in the past; C: newly diagnosed untreated paucibacillary $(\mathrm{PB})(\mathrm{n}=93)$; D: household contacts $(\mathrm{HHC})$ of MB patients $(\mathrm{n}=192)$; $\mathrm{E}$ : endemic controls (EC) $(\mathrm{n}=282)$. IgG antibodies to M. leprae protein antigens and IgM antibodies to PGL-I were detected by ELISA. Each point represents the mean optical density (OD) of duplicates of each individual serum sample. The median OD value of each group is represented by the horizontal line and the traced line represents the cut-off $(\mathrm{OD}>0.3)$. The number above each data set is the percent positive responses. 
sion proteins. Moreover, the serologic reactivity to these proteins was validated in an expanded population with distinct ethnic backgrounds recruited from two highly endemic regions in Brazil. Our results are encouraging because they serve to elucidate the potential for development of an improved serologic test that could be widely applicable for leprosy testing in Brazil.

Our results indicate that the addition of a protein antigen to PGL-I in the composition of a serologic test can enhance the sensitivity of the test to MB leprosy. Although similar positivity rates were detected for PGL-I vs. LID-1, ML0405 and 46f proteins among MB leprosy patients, some MB leprosy patients with negative antiPGL-I serology had antibodies that recognised $M$. leprae proteins. Five out of $10 \mathrm{MB}$ leprosy patients who were seronegative for anti-PGL-I (OD range 0-0.26) were responsive to LID-1 and four of these patients had antibodies to ML0405, 46f and 92f. Thus, in theory, the positivity rate in MB leprosy patients could increase from $83-91 \%$ if a combination of the LID-1 antigen and PGL-I is used.

In this survey, different study groups from each endemic site were screened (e.g., Rondonópolis) (Fig. 3A-E) and different degrees of seroreactivity were observed. MB patients were found to be the most responsive, followed by the post-MDT, PB, HHC and EC groups. In $\mathrm{MB}$ and $\mathrm{PB}$ leprosy patients, this ranking by serologic response likely reflects the bacillary load. Among uninfected controls, this ranking probably reflects the higher levels of exposure in HHCs than in healthy ECs.

A previous study among Brazilian individuals followed patients who were undergoing MDT for five months (Duthie et al. 2011) and showed a more pronounced decline in the antibody titres to proteins than to PGL-I. In our study, the median ODs for PGL-I among post-MDT groups from Rondonópolis and Prata Village were lower, resulting in lower positivity levels compared to LID-1 (14\% PGL-I vs. 42\% LID-1 in Rondonópolis; 8\% PGL-I vs. 35\% LID-1 in Prata Village) and suggesting that anti-PGL-I antibodies declined more over time. However, the median OD for LID-1 among MB patients was almost twice as high as the median OD for PGL-I (1.6 vs. 0.74 ) and the positivity for PGL-I in this group was lower than for LID-1 ( $83 \%$ vs. $89 \%$ ), which might account for the much lower percentage of PGL-I positivity

\section{TABLE}

Positive responses to ligand-induced degradation-1 (LID-1) and phenolic glycolipid-I (PGL-I) antigens among multibacillary and paucibacillary leprosy patients from Rondonópolis, state of Mato Grosso, Brazil

\begin{tabular}{lcc}
\hline Positivity & MB & PB \\
\hline LID-1 (\%) & 89 & 7 \\
Median OD (range) & $1.6(0.03-3.0)$ & $0.11(0.01-0.8)$ \\
PGL-I (\%) & 83 & 8 \\
Median OD (range) & $0.74(0.03-1.55)$ & $0.03(0.01-0.51)$ \\
\hline
\end{tabular}

OD: optical density. among post-MDT individuals. Moreover, the discrepancies that were observed in the decline of antibody levels between these two studies could be attributed to the use of different PGL-I antigens (ND-O-BSA vs. NT-P-BSA) and differences in ELISAs, including cut-off points and differences in the study populations.

A study by Duthie et al. (2011) also showed uniformly low responses to LID-1 and ML0405 protein antigens in a Venezuelan post-MDT group and in a few individuals, the high serological response post-MDT was associated with irregular or shorter treatment. Compared to that study, we found relatively higher seropositivity levels after treatment. In our study, the number of years posttreatment did not negatively correlate with the seropositivity level and we do not have enough background data to infer whether incorrect treatment or relapse among seropositive post-MDT individuals was a factor. Since our study was not designed to evaluate the effect of time on antibody responses, analyses of individuals against an entire group, where the magnitude of response is variable, could be misleading and might not be appropriate for determining outcomes. To analyse the effect of time on the decay of antibody levels post-MDT, individual patient serological responses need to be monitored both during and after MDT.

Potential cross-reactivity is an important consideration when new antigens are screened for diagnostic purposes, particularly for countries with a high incidence of $\mathrm{TB}$, high BCG vaccination coverage and high levels of exposure to non-pathogenic environmental mycobacteria (Geluk et al. 2005, Araoz et al. 2006b). To avoid crossreactivity, several investigators have focused on the selection and evaluation of $M$. leprae antigens based on the lack of sequence homology with proteins from other mycobacteria. Using this reasoning, antigens that have no homologue in Mycobacterium tuberculosis or other known mycobacteria have been selected for further analysis as diagnostic candidates for leprosy (Geluk et al. 2005, Spencer et al. 2011). However, several groups, including our

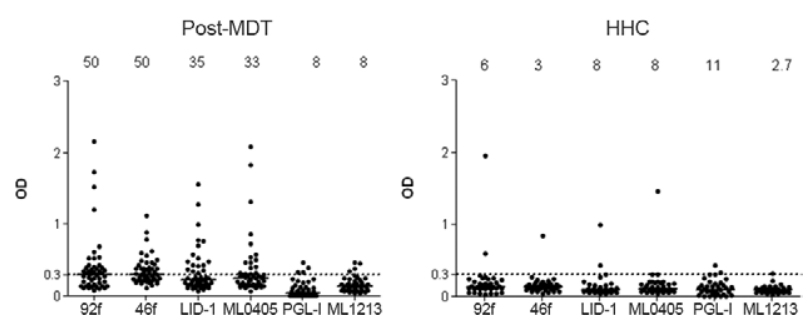

Fig. 4: serologic reactivity to Mycobacterium leprae protein antigens - 92f, 46f, leprosy IDRI diagnostic-1 (LID-1), ML0405, phenolic glycolipid-I (PGL-I) and ML1213 - among participants from Prata Village, state of Pará, northern region Brazil. A: post-multidrug therapy (MDT) $(n=47)$ individuals previously diagnosed as multibacillary (MB) leprosy that received MDT in the past; B: household contacts (HHC) of MB patients $(n=36)$. IgG antibodies to M. leprae protein antigens and IgM antibodies to PGL-I were detected by ELISA. Each point represents the mean optical density (OD) of duplicates of each individual serum sample. The median OD value of each group is represented by the horizontal line and the traced line represents the cut-off (OD $>0.3)$. The number above each data set is the percent positive responses. 
own, have demonstrated that in silico predictions of sequence homology with other mycobacteria do not clearly predict cross-reactivity under field conditions (Geluk et al. 2005, Sampaio et al. 2011). Despite possessing homology with proteins from other mycobacterial species, the new $M$. leprae fusion proteins described here were not recognised by the majority of EC, TB and HHC patients within $\mathrm{GO}$, an area of high BCG vaccination coverage. Low response rates among ECs and HHCs were also observed in different endemic areas for leprosy in PA and MT. At this point, we cannot exclude the possibility that the few positive responses among $\mathrm{EC}$ and TB patients were due to either cross-reactivity with environmental mycobacterial antigens or co-infection with $M$. leprae.

Another important issue to consider in the screening of genes or protein/peptide antigens for wide diagnostic purposes is the presence of amino acid motifs that predict high-affinity binding to multiple HLA class II molecules. This would increase the chances of antigen recognition by $\mathrm{T}$ cells from different immunogenetic backgrounds, facilitating antibody production. Screening studies of immunoreactivity to new $M$. leprae protein antigens have tested patients and controls with different immunogenetic backgrounds from Brazil (GO, Bahia, Minas Gerais and Rio de Janeiro), the Philippines, Korea, Mali and Bangladesh (Araoz et al. 2006a, b, Duthie et al. 2007, 2010, 2011, Geluk et al. 2009, 2010). The widespread screening of $M$. leprae proteins and peptides to identify sequences that are immunogenic in the context of multiple HLA alleles could identify antigens that are suitable for a diagnostic test with the greatest utility in different geographical regions. Further analyses of patients with different backgrounds, such as HLA typing, could provide additional insight into the impact of ethnic background on seroreactivity to different antigens.

One important issue regarding the detection of $\operatorname{IgG}$ antibodies to M. leprae proteins is their potential to be used as detectors for infections in the early stages. Untreated MB patients can shed and spread viable bacteria via the airways and HHCs of MB patients have a higher risk of developing clinical leprosy than HHCs of PB patients (Fine et al. 1997). A specific and sensitive serologic test that could indicate asymptomatic infection would have a positive impact on public health, reducing both transmission sources due to MDT treatment and physical disabilities due to late diagnosis. Positive antiPGL-I serology among MB patients and HHCs has been described as a risk factor for leprosy; however, this risk factor does not always correlate with the development of leprosy (Cho et al. 2001, Bührer-Sékula et al. 2003, Oskam et al. 2003). We observed similar IgG positivity among HHCs from MT, GO and PA. These results again suggest that a combination of antigens to detect leprosyspecific responses could be best suited to identify asymptomatic infection and predict disease progression.

The results of our study, together with data from other groups, indicate that newly identified $M$. leprae antigens may contribute to the development of a serologic test with an improved ability to identify $M$. leprae infection. In this regard, the development of rapid protein-based serologic tests to detect specific IgG should complement the PGL-I test that detects IgM antibodies and this combination could be used in non-specialised settings as a point-of-care test in field conditions. Finally, the discovery of M. leprae protein antigens that can be recognised across different ethnic backgrounds within a highly endemic setting demonstrates that new laboratory tools are being described that could contribute to leprosy control programs.

\section{ACKNOWLEDGEMENTS}

To Greg Ireton, Jeff Guderian, Raodoh Mohamath and Ayesha Misquith (IDRI, USA), for the production of high quality recombinant proteins, to Dr Tsuyoshi Fujiwara (Nara University, Japan), for generously providing the NT-P-BSA antigen, and to the patients and staff of the Reference Center for Diagnostics and Therapeutics, Goiânia, for their cooperation and support during recruitment.

\section{REFERENCES}

Araoz R, Honore N, Banu S, Demangel C, Cissoko Y, Arama C, Uddin MK, Hadi SK, Monot M, Cho SN, Ji B, Brennan PJ, Sow S, Cole ST 2006a. Towards an immunodiagnostic test for leprosy. Microbes Infec 8: 2270-2276.

Araoz R, Honore N, Cho S, Kim JP, Cho SN, Monot M, Demangel C, Brennan PJ, Cole ST 2006b. Antigen discovery: a postgenomic approach to leprosy diagnosis. Infect Immun 74: 175-182.

Barreto ML, Teixeira MG, Bastos FI, Ximenes RAA, Barata RB, Rodrigues LC 2011. Successes and failures in the control of infectious diseases in Brazil: social and environmental context, policies, interventions and research needs. Lancet 377: 1877-1889.

Bührer-Sékula S, Hamerlinck FF, Out TA, Bordewijk LG, Klatser PR 2000. Simple dipstick assay for semi-quantitative detection of neopterin in sera. J Immunol Methods 238: 55-58.

Bührer-Sékula S, Smits HL, Gussenhoven GC, van Ingen CW, Klatser PR 1998. A simple dipstick assay for the detection of antibodies to phenolic glycolipid I of Mycobacterium leprae. Am J Trop Med Hyg 58: 133-136.

Bührer-Sékula S, Smits HL, Gussenhoven GC, van Leeuwen J, Amador S, Fujiwara T, Klatser PR, Oskam L 2003. Simple and fast lateral flow test for classification of leprosy patients and identification of contacts with high risk of developing leprosy. J Clin Microbiol 41: 1991-1995.

Bührer-Sékula S, Visschedijk J, Grossi MA, Dhakal KP, Namadi AU, Klatser PR, Oskam L 2007. The ML flow test as a point of care test for leprosy control programmes: potential effects on classification of leprosy patients. Lepr Rev 78: 70-79.

Cho SN, Cellona RV, Villahermosa LG, Farjado TT, Balagon MVF, Abalos RM, Tan EV, Walsh GP, Kim JD, Brennan PJ 2001. Detection of phenolic glycolipid I of Mycobacterium leprae in sera from leprosy patients before and after start of multidrug therapy. Clin Diagn Lab Immunol 8: 138-142.

Duthie MS, Goto W, Ireton GC, Reece ST, Cardoso LP, Martelli CM, Stefani MM, Nakatani M, de Jesus RC, Netto EM, Balagon MV, Tan EV, Gelber RH, MaedaY, Makino M, Hoft D, Reed SG 2007. Use of protein antigens for early serological diagnosis of leprosy. Clin Vaccine Immunol 14: 1400-1408.

Duthie MS, Goto W, Ireton GC, Reece ST, Sampaio LHS, Grassi AB, Sousa ALM, Martelli CMT, Stefani MMA, Reed EG 2008a. Antigen-specific T-cell responses of leprosy patients. Clin Vaccine Immunol 15: 1659-1665.

Duthie MS, Hay MN, Morales CZ, Carter L, Mohamath R, Ito L, Oyafuso LK, Manini MI, Balagon MV, Tan EV, Saunderson PR, 
Reed SG, Carter D 2010. Rational design and evaluation of a multiepitope chimeric fusion protein with the potential for leprosy diagnosis. Clin Vaccine Immunol 17: 298-303.

Duthie MS, Hay MN, Rada EM, Convit J, Ito L, Oyafuso LKM, Manini MIP, Goulart IMB, Lobato J, Goulart LR, Carter D, Reed SG 2011. Specific IgG antibody responses may be used to monitor leprosy treatment efficacy and as recurrence prognostic markers. Eur J Clin Microbiol Infect Dis 10: 1257-1265.

Duthie MS, Ireton GC, Kanaujia GV, Goto W, Liang H, Bhatia A, Busceti JM, MacDonald M, Neupane KD, Ranjit C, Sapkota BR, Balagon M, Esfandiari J, Carter D, Reed SG 2008b. Selection of antigens and development of prototype tests for point-of-care leprosy diagnosis. Clin Vaccine Immunol 15: 1590-1597.

Fine PE, Sterne JA, Ponnighaus JM, Bliss L, Saui J, Chihana A, Munthali M, Warndorff DK 1997. Household and dwelling contact as risk factors for leprosy in northern Malawi. Am J Epidemiol 146: 91-102.

Geluk A, Klein MR, Franken KL, van Meijgaarden KE, Wieles B, Pereira KC, Bührer-Sékula S, Klatser PR, Brennan PJ, Spencer JS, Williams DL, Pessolani MC, Sampaio EP, Ottenhoff TH 2005. Postgenomic approach to identify novel Mycobacterium leprae antigens with potential to improve immunodiagnosis of infection. Infect Immun 73: 5636-5644.

Geluk A, Ottenhoff TH 2006. HLA and leprosy in the pre and postgenomic eras. Hum Immunol 67: 439-445.

Geluk A, Spencer JS, Bobosha K, Pessolani MC, Pereira GM, Banu S, Honore N, Reece ST, Macdonald M, Sapkota BR, Ranjit C, Franken KL, Zewdie M, Aseffa A, Hussain R, Stefani MM, Cho SN, Oskam L, Brennan PJ, Dockrell HM 2009. From genome-based in silico predictions to ex vivo verification of leprosy diagnosis. Clin Vaccine Immunol 16: 352-359.

Geluk A, van der Ploeg-van Schip JJ, van Meijgaarden KE, Commandeur S, Drijfhout JW, Benckhuijsen WE, Franken KL, Naafs B, Ottenhoff TH 2010. Enhancing sensitivity of detection of immune responses to Mycobacterium leprae peptides in whole-blood assays. Clin Vaccine Immunol 17: 993-1004.

IBGE - Instituto Brasileiro de Geografia e Estatística 2010. Censo 2010. [accessed 10 February 2012]. Available from: ibge.gov.br/ estadosat.

Kerr-Pontes LR, Montenegro AC, Barreto ML, Werneck GL, Feldmeier H 2004. Inequality and leprosy in Northeast Brazil: an ecological study. Int J Epidemiol 33: 262-269.

Lázaro FP, Werneck RI, Marcket CCO, Cobat A, Prevedello FC, Pimentel RP, Macedo GMM, Eleutério MAM, Vilar G, Abel L, Xavier MB, Alcais A, Mira MT 2010. A major gene controls leprosy susceptibility in a hyperendemic isolated population from north of Brazil. J Infect Dis 201: 1598-1605.

MS/SVS - Ministério da Saúde/Secretaria de Vigilância em Saúde 2009. Relatório de Situação Mato Grosso. [accessed 5 Febru- ary 2012]. Available from: portal.saude.gov.br/portal/arquivos/ pdf/005_mt_relatorio_de_situacao.pdf.

MS/SVS - Ministério da Saúde/Secretaria de Vigilância em Saúde 2011. Relatório de Situação Goiás. [accessed 2 February 2012]. Available from: portal.saude.gov.br/portal/arquivos/pdf/12_ Goiás_final.pdf.

Oskam L, Slim E, Bührer-Sékula S 2003. Serology: recent developments, strengths, limitations and prospects: a state of the art overview. Lepr Rev 74: 196-205.

Reece ST, Ireton G, Mohamath R, Guderian J, Goto W, Gelber R, Groathouse N, Spencer J, Brennan P, Reed SG 2006. ML0405 and ML2331 are antigens of Mycobacterium leprae with potential for diagnosis of leprosy. Clin Vaccine Immunol 13: 333-340.

Ridley DS, Jopling WH 1966. Classification of leprosy according to immunity. A five-group system. Int J Lepr Other Mycobact Dis 34: 255-273.

Sampaio LH, Stefani MM, Oliveira RM, Sousa AL, Ireton GC, Reed SG, Duthie MS 2011. Immunologically reactive $M$. leprae antigens with relevance to diagnosis and vaccine development. $B M C$ Infect Dis 11: 26.

Scollard DM, Adams LB, Gillis TP, Krahenbuhl JL, Truman RW, Williams DL 2006. The continuing challenges of leprosy. Clin Microbiol Rev 19: 338-381.

Silva EA, Iyer A, Ura S, Lauris JR, Naafs B, Das PK, Vilani-Moreno F 2007. Utility of measuring serum levels of anti-PGL-I antibody, neopterin and C-reactive protein in monitoring leprosy patients during multidrug treatment and reactions. Trop Med Int Health 12: $1450-1458$

Spencer JS, Dockrell HM, Kim HJ, Marques MA, Williams DL, Martins MV, Martins ML, Lima MC, Sarno EN, Pereira GM, Matos H, Fonseca LS, Sampaio EP, Ottenhoff TH, Geluk A, Cho SN, Stoker NG, Cole ST, Brennan PJ, Pessolani MC 2005. Identification of specific proteins and peptides in Mycobacterium leprae suitable for the selective diagnosis of leprosy. J Immunol 175: 7930-7938.

Spencer JS, Kim HJ, Wheat WH, Chatterjee D, Balagon MV, Cellona RV, Tan EV, Gelber R, Saunderson P, Duthie MS, Reece ST, Burman W, Belknap R, Kenzie WRM, Geluk A, Oskan L, Dockrell HM, Brennan PJ 2011. Analysis of antibody responses to Mycobacterium leprae phenolic glycolipid I, lipoarabinomannan and recombinant proteins to define disease subtype-specific antigenic profiles in leprosy. Clin Vaccine Immunol 2: 260-267.

Stefani MMA 2008. Challenges in the post genomic era for the development of tests for leprosy diagnosis. Rev Soc Bras Med Trop 41 (Suppl. II): 89-94.

WHO - World Health Organization 1991. Multidrug therapy for leprosy 1991. Bull WHO 69: 263-269.

WHO - World Health Organization 2011. Global leprosy situation 2010. Wkly Epidemiol Rec 85: 389-400.

Young DB, Buchanan TM 1983. A serological test for leprosy with a glycolipid specific for Mycobacterium leprae. Science 221: 1057-1059. 